\title{
EE
}

PAPER - OPEN ACCESS

\section{Evaluasi Efektivitas Pasca Huni Penghuni Perumahan Subsidi Dengan Pendekatan Ekonomi}

\author{
Author \\ : Dwira Nirfalini Aulia dan Putri Andriani Hrp \\ DOI \\ : 10.32734/ee.v3i1.850 \\ Electronic ISSN \\ : 2654-704X \\ Print ISSN \\ : 2654-7031
}

Volume 3 Issue 1 - 2020 TALENTA Conference Series: Energy \& Engineering (EE)

This work is licensed under a Creative Commons Attribution-NoDerivatives 4.0 International License.

Published under licence by TALENTA Publisher, Universitas Sumatera Utara

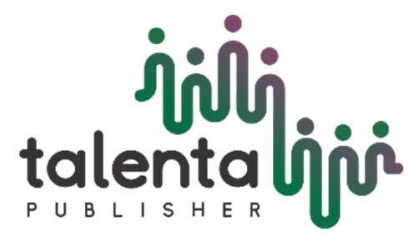




\title{
Evaluasi Efektivitas Pasca Huni Penghuni Perumahan Subsidi Dengan Pendekatan Ekonomi
}

\author{
Evaluation of Post-Habitiveness Effectiveness of Subsidized Housing Residents Using \\ an Economic Approach
}

\author{
Dwira Nirfalini Aulia ${ }^{1}$, Putri Andriani Hrp ${ }^{1}$ \\ Departemen Arsitektur, Fakultas Teknik Universitas Sumatera Utara, Jalan. Perpustakaan, Kampus USU Gedung D, Padang Bulan, Medan Baru, \\ Kota Medan, Sumatera Utara 20155, Indonesia \\ *dwira_aulia@yahoo.com,hrp_putri@yahoo.com
}

\begin{abstract}
Abstrak
Indonesia telah terbagi atas beberapa daerah, dan pada setiap daerah sudah banyak dibangun perumahan. Khususnya daerah di kota Medan, Sumatera Utara yang sudah banyak perumahan yang telah dibangun khususnya tempat tinggal bagi masyarakat kota Medan yang berpenghasilan rendah (MBR). Dengan munculnya pembangunan dapat menumbuhkan pertumbuhan ekonomi, dan tersedianya lapangan pekerjaan.Pembangunan infrastruktur merupakan perihal berarti dalam tata cara perkembanganan sesuatu bangsa yang baik pada zona ekonomi, budya, sosial, pembelajaran, pertanian serta zona yang lain. Riset ini bertujuan agar mengenali rumah subsidi yang bisa dijangkau oleh penghuni MBR serta buat mengenali aspek kepuasan penghuni MBR terhadap pembelian rumah subsidi.Metode yang digunakan yaitu deskriptif kuantitatif, yaitu memakai survey data informasi primer dan mewawancarai kepada narasumber. Hasil riset ini diharapkan bisa memberikan manfaat, antara lain meningkatkan pengetahuan bagi peneliti tentang keadaan sosial serta ekonomi bagi penduduk di perumahan subsidi di daerah Perumahan Hijau 3
\end{abstract}

Kata kunci:evaluasi, perumahan subsidi, masyarakat;

\begin{abstract}
Indonesia has been divided into several regions, and in each region many houses have been built. Especially in the city of Medan, North Sumatra, which has built a lot of housing, especially housing for the people of Medan city with low income (MBR). With the advent of development, it can foster economic growth, and the availability of jobs. Infrastructure development is an important factor in a nation's good growth methods in the economic, social, cultural, educational, agricultural and other sectors. This study aims to determine the subsidized houses that can be reached by MBR residents and to determine the satisfaction factor of MBR residents for the purchase of subsidized houses. The method used is descriptive quantitative, using primary data surveys and interviewing informants. The results of this study are expected to provide benefits, including increasing knowledge insight for writers about the social and economic conditions for residents in subsidized housing in the Green Housing area 3
\end{abstract}

Keywords: evaluation, subsidized housing, community;

\section{Pendahuluan}

Indonesia telah terbagi atas beberapa daerah, dan pada setiap daerah sudah banyak dibangun perumahan. Khususnya daerah di kota Medan, Sumatera Utara yang sudah banyak perumahan yang telah dibangun khususnya tempat tinggal 
bagi masyarakat kota Medan yang berpenghasilan rendah (MBR). Salah satunya Perumahan subsidi merupakan sarana dan prasarana yang dibantu oleh pemerintah bagi Masyarakat Berpenghasilan Rendah sebagai lingkungan tempat tinggal.

Terjadinya pembangunan infrastruktur merupakan sesuatu indikator untuk perkembangan suatu negara. Dalam rencana pembangunan infrastruktur terdapat sebagian dari pendukung program di bidang lain. Dengan munculnya pembangunan bisa meningkatkan pertumbuhan di ekonomi, dan tersedianya lapangan pekerjaan[5]. Pembangunan infrastruktur termasuk suatu yang penting dalam metode pertumbuhan pada suatu bangsa yang baik untuk sektor ekonomi, budaya, sosial, pendidikan, pertanian serta sektor lainnya.Peranan aktif untuk pemerintah, dan masyarakat yang diperlukan untuk terjadinya pembangunan infrastruktur berkelanjutan.

Salah satu peranan pemerintah yang dibutuhkan untuk pembangunan infrastruktur ialah dengan menentukan anggaran dalam pembangunan dan terbentuknya preservasi infrastruktur.Infrastruktur yang dimaksud adalah pekerjaan umum dan perumahan rakyat.

Perumahan dan permukiman yaitu termasuk dari salah satu pokok keperluan dasar manusia yang memiliki manfaat strategis untuk peran sebagai pokok pendidikan keluarga serta peningkatan bagi kualitas generasi di masa depan. Dengan terwujudnya kesejahteraan masyarakat serta sumber daya manusia yang berkualitas dengan ditandai ada peningkatan kualitas hidup yang baik atau layak.

\section{Tinjauan Pustaka}

Perumahan dan permukiman tentu tidak hanya bisa dilihat sebagai kebutuhan kehidupan sekedar, namun lebih dari itu ialah salah satu proses bermukimnya manusia dalam menciptakan sebuah ruang kehidupan untuk bersosialisasi dirinya serta menampakkan jati diri. Proses penyediaannya wajib dikelola serta dikendalikan oleh Pemerintah supaya penggunaan serta pemanfaatannya bisa dijangkau masyarakat secara adil dan merata tidak harus menimbulkan kesenjangan ekonomi serta sosial dalam proses bermukimnya warga.

\subsection{Evaluasi Pasca Huni dalam Pembangunan Perumahan}

Sudibyo menjelaskan bahwa evaluasi pasca huni adalah kegiatan yang mengkaji (meninjau) evaluasi pada bangunanbangunan ataupun lingkungan binaan yang sudah ditinggal [4]. Evaluasi pasca huni penting untuk mendukung pada pembangunan berikutnya. Dilihat dari sisi penghuni ataupun dari sisi pemerintahan juga yang menangani dalam kasus perumahan bersubsidi.

\subsection{Pemukiman Bersubsidi}

Perumahan merupakan kelompok rumah yang berguna sebagai area tempat tinggal ataupun hunian yang difasilitasi dengan prasarana lingkungan, yakni kecukupan dasar fisik lingkungan, contohnya pembuangan sampah, persediaan air, dan saluran pembuangan air yang teratur serta fasilitas umum yang mendukung lainnya[6]. Pemerintah melalui Kementrian Pekerjaan Umum dan Perumahan Rakyat (PUPR) bakal memberikan dorongan kepada developer yang telah membangun perumahan dalam bentuk tempat tinggal dengan mendirikan progam satu juta rumah. Selanjutnya itu juga dapat mempermudah dalam perizinan dalam membangun rumah MBR atau biasa disebut sebagai rumah subsidi. Pentingnya dilakukan penelitian ini agar semua dalam pelaksanaan perumahan subsidi berjalan dengan lancar. Ini bisa dilihat dari kondisi yang sudah ada di perumahan subsidi yang tidak semua rumahnya ditinggal oleh pemiliknya namun ada juga disewakan, kosong tidak berpenghuni dan disita dengan pihak bank yang berwewenang.

\subsection{Teori (efektivitas) pencapaian tujuan dalam pemberian rumah subsidi}

Definisi efektivitas merupakan suatu keadaan yang mengakibatkan yang dikehendaki jika seseorang melakukan sesuatu perbuatan, dinyatakan efektif apabila menimbulkan maksud tujuan yang diharapkan.

Ada beberapa jenis efektivitas dengan sistem pembayaran KPR dalam perumahan subsidi, penilaian serta pengukuran bisa dilihat dari: 


\subsubsection{Kesiapan sumber daya}

Sebuah sistem bisa dikatakan efisien apabila ditunjang dengan adanya kesiapan pada sumber daya. Bisa ditinjau dari bersumber dari kesiapan infrastruktur finansial pendukung dalam sistem biaya yang bergantung pada:

- Terdapat sumber biaya perumahan dalam jangka panjang

- Lembaga keuangan dapat berpartisipasi dalam sistem pembayaran KPR dalam pengadaan perumahan subsidi

- Adaya strategi yang mengatur pembayaran KPR dalam pengadaan perumahan subsidi

\subsubsection{Kemudahan}

Sebuah sistem bisa dikatakan efisien apabila metode pembayaran dalam pengadaan perumahan subsidi dalam metode tersebut mudah dilakukan oleh Stakeholder yang berkaitan pada sistem pembayaran tersebut.

Stakeholder yang dimaksud yaitu:

- Lembaga keuangan (bank yang memanifestasikan KPR)

- Developer ( Perumnas dan pengembang swasta)

- Masyarakat ataupun warga ( kelompok sasaran terhadap perumahan subsidi)

\subsubsection{Ketepatan sasaran}

Persiapan yang harus dievaluasi yang bertujuan agar memahami apakah sudah jelas, singkat, akurat dan nyata. Yang terdapat beragam keputusan serta aktifitas manajemen lainnya hanya efisien apabila berdasarkan terhadap laporan yang tepat, yakni tepatnya penyediaan KPR subsidi untuk keluarga yang baru memiliki rumah serta dalam golongan MBR (masyarakat berpenghasilan rendah)[2].

\subsubsection{Keterjangkauan}

Menurut Mangeswuri terdapatnya keterjangkauan masyarakat pada rumah yang ingin diamati dalam kemampuan pengadaan perumahan terhadap semua golongan masyarakat [3]. Keterjangkauan pada rumah termasuk salah satu upaya dan kemauan suatu rumah tangga dalam mengeluarkan sebagian hasil pendapatannya untuk pembayaran perumahan.Adanya dorongan yang sangat dekat serta saling mempengaruhi diantara rumah tangga, keuangan rumah tangga serta rumah yang diharapkan.

\subsection{Golongan Masyarakat Berpenghasilan Rendah (MBR) di daerah Perkotaan}

Bagi warga yang tinggal didaerah perkotaan terdiri dari beberapa golongan masyarakat yang berbeda tingkatan sosialekonominya.Dalam golongan MBR yang hanya mampu menempatkan lokasi yang lumayan jauh dari pusat kegiatan kota, yang sulit mendapatkan sarana dan prasarana kota yang memadai serta jauh dari sumber lapangan kerja. Sementara itu, sejarah telah membuktikan lumayan banyak manfaat yang bisa didapat masing-masing golongan masyarakat yang berada disatu kawasan daerah permukiman yang sama.Ketentuan golongan sasaran terbagi menjadi 3, bersumber pada tingkat penghasilan tersebut, yaitu:

Tabel 2.1 Peraturan Menteri Negara Perumahan Rakyat pada tahun 2006

\begin{tabular}{ll}
\hline Kelompok sasaran & Batasan penghasilan $($ Rp/Bulan) \\
\hline I & $1.500 .000 \leq$ Penghasilan $\leq 2.000 .000$ \\
\hline II & $800.000 \leq$ Penghasilan $<1.400 .000$ \\
\hline III & Penghasilan $<800.000$ \\
\hline
\end{tabular}




\subsection{Definisi Kredit Pemilikan Rumah (KPR)}

Kredit pemilikan rumah merupakan sesuatu fasilitas yang mempunyai pinjaman uang yang diperoleh dari pihak perbankan kepada nasabah yang akan dimanfaatkan sebagai pembelian atau untuk merenovasi rumah dengan syarat dan ketentuan tertentu. Dengan adanya KPR, masyarakat tidak sulit dalam memiliki rumah sendiri karena dengan adanya fasilitas kredit yang sudah diperoleh dari kalangan perbankan[2].

\section{Metodologi}

Metode penelitian yang akan digunakan pada penelitian ini ialah penelitian kuantitatif, yakni suatu cara pengambilan datanya digunakan dengan menggunakan survey data primer, data yang termasuk data yang didapatkan langsung dari data sumber asli ataupun fakta yang mencerminkan keadaan sebenarnya di daerah Perumahan Hijau 3. Dengan penelitian langsung diperoleh dari sumber data yang langsung dengan menggunakan penelitian yang dilakukan, yaitu dengan mewawancarai terhadap narasumber pada objek penelitian tersebut dan membagikan kuesioner. Penelitian deskriptif yakni dilakukan untuk mengenal karakteristik golongan dalam keadaan tertentu, berpikir secara sistematis tentang bagian-bagian dalam keadaan tertentu, memberikan ide saran dalam penelitian serta dapat mendapatkan keputusan sederhana. Penelitian deskriptif adalah penelitian yang bertujuan untuk menjelaskan data secara tersusun dan akurat sehingga memberikan gambaran yang jelas dengan pendekatan kuantitatif[5].

\section{Pembahasan}

\subsection{Profil responden}

Responden yang didata dalam penelitian yang tinggal di Perumahan Hijau 3

berdasarkan dari sampel berjumlah 75 orang. Dengan jenis responden terperinci berdasarkan dari umur, jenis kelamin, lama tinggal, pekerjaan, pendidikan terakhir, serta jumlah anggota keluarga..

\subsubsection{Karakteristik (jenis) pada responden berdasarkan umur}

Dari 75 sampel orang yang dijadikan responden bisa diketahui bahwa karakteristik (jenis) responden berdasarkan umur, yaitu:

Tabel 4.1 Karakteristik (jenis) responden berdasarkan umur

\begin{tabular}{lll}
\hline Umur (tahun) & Orang(jumlah) & Presentase (\%) \\
\hline $\mathbf{2 0 - 2 9}$ & 21 & $28 \%$ \\
\hline $\mathbf{3 0 - 3 9}$ & 24 & $32 \%$ \\
\hline $\mathbf{4 0 - 4 9}$ & 23 & $31 \%$ \\
\hline $\mathbf{5 0 - 5 9}$ & 7 & $9 \%$ \\
\hline Total & $\mathbf{7 5}$ & $100 \%$ \\
\hline
\end{tabular}

\subsubsection{Karakteristik (jenis) pada responden berdasarkan jenis kelamin}

Dari 75 sampel orang yang dijadikan responden bisa diketahui bahwa karakteristik (jenis) responden berdasarkan jenis kelamin, yaitu: 
Tabel 4.2 Karakteristik (jenis) responden berdasarkan jenis kelamin

\begin{tabular}{lll}
\hline Jenis kelamin & Orang(jumlah) & Presentase (\%) \\
\hline Laki-laki (pria) & 43 & $57 \%$ \\
\hline Perempuan (wanita) & 32 & $43 \%$ \\
\hline Total & $\mathbf{7 5}$ & $100 \%$ \\
\hline
\end{tabular}

\subsubsection{Karakteristik (jenis) pada responden berdasarkan jenis lama tinggal}

Responden dalam penelitian ini merupakan termasuk masyarakat Perumahan Hijau 3 yang menempati perumahan pada tahun 2019. Berikut ini adalah termasuk data responden berdasarkan dari lama tinggal, yaitu:

Tabel 4.3 Karakteristik (jenis) responden berdasarkan jenis kelamin

\begin{tabular}{lll}
\hline Lama tinggal (tahun) & Orang(jumlah) & Presentase (\%) \\
\hline$<\mathbf{1}$ Tahun & 11 & $15 \%$ \\
\hline $\mathbf{1 - 2}$ Tahun & 20 & $26 \%$ \\
\hline $\mathbf{2 - 2 , 5}$ Tahun & 34 & $46 \%$ \\
\hline $\mathbf{2 , 5 - 3}$ Tahun & 10 & $13 \%$ \\
\hline Total & $\mathbf{7 5}$ & $100 \%$ \\
\hline
\end{tabular}

\subsubsection{Karakteristik (jenis) pada responden berdasarkan jenis pekerjaan}

Masyarakat Perumahan Hijau 3 yang dipilih menjadi responden mempunyai jenis pekerjaan yang beragam variasi, mulai dari karyawan, pegawai negri dan ada yang bekerja sebagai wiraswasta. Berikut ini adalah termasuk data responden, yaitu:

Tabel 4.4 Karakteristik (jenis) responden berdasarkan jenis pekerjaan

\begin{tabular}{lll}
\hline Pekerjaan & Orang (jumlah) & Presentase (\%) \\
\hline Buruh & 5 & $7 \%$ \\
\hline Freelancer & 3 & $5 \%$ \\
\hline Guru & 6 & $9 \%$ \\
\hline Karyawan & 13 & $20 \%$ \\
\hline Perawat & 2 & $3 \%$ \\
\hline PNS & 7 & $10 \%$ \\
\hline Wiraswasta & 15 & $22 \%$ \\
\hline Pegawai & 10 & $14 \%$ \\
\hline Pedagang & 14 & $19 \%$ \\
\hline
\end{tabular}

\subsubsection{Karakteristik (jenis) pada responden berdasarkan jenis pendidikan terakhir}

Masyarakat Perumahan Hijau 3 yang dipilih menjadi responden yaitu orang-orang yang berpendidikan, meskipun responden yang memiliki latar belakang pendidikan yang bermacam-macam. Diawali dari tingkat Sekolah Dasar (SD) 
sampai dengan Strata Satu (S1). Dan berikut inilah yang merupakan termasuk data pendidikan terakhir bagi responden, yaitu:

Tabel 4.5 Karakteristik (jenis) responden berdasarkan jenis pendidikan terakhir

\begin{tabular}{lll}
\hline Pendidikan terakhir & Orang (jumlah) & Presentase (\%) \\
\hline SD & 1 & $3 \%$ \\
\hline SMP/Sederajat & 6 & $8 \%$ \\
\hline SMA/Sederajat & 25 & $33 \%$ \\
\hline D1 & 6 & $8 \%$ \\
\hline D3 & 8 & $10 \%$ \\
\hline S1 & 29 & $38 \%$ \\
\hline Total & 75 & $100 \%$ \\
\hline
\end{tabular}

\subsubsection{Karakteristik (jenis) pada responden berdasarkan jumlah anggota keluarga}

Masyarakat Perumahan Hijau 3 terdiri dari responden yang belum berkeluarga maupun sudah berkeluarga. Berikut ini yang merupakan data jumlah pada anggota keluarga responden, yaitu:

Tabel 4.6 Karakteristik (jenis) responden berdasarkan jumlah anggota keluarga

\begin{tabular}{|c|c|c|}
\hline Jumlah anggota keluarga (Orang) & Orang (jumlah) & Presentase (\%) \\
\hline 1 & 6 & $8 \%$ \\
\hline 2 & 10 & $13 \%$ \\
\hline 3 & 28 & $28 \%$ \\
\hline 4 & 21 & $13 \%$ \\
\hline 5 & 10 & $100 \%$ \\
\hline
\end{tabular}

Dalam sebuah program tentu dinilai sejauh mana tingkat dari efektivitas kebijakan tersebut, dan selain dari itu program tersebut tentu saja mempunyai dampak bagi orang yang melakukannya.

1. Analisis mengenai efektivitas program KPR subsidi di Perumahan Hijau 3Untuk efektivitas dalam ketepatan sasaran program KPR Subsidi dengan tingkat penghunian di Perumahan Hijau 3 di analisis dengan menggunakan metode rumus efektivitas untuk mencari rasio efektivitas dan mengetahui tingkat pencapaian efektivitasnya.

2. Ketepatan sasaran program KPR Subsidi dengan bantuan FLPP

3. Ketepatan sasaran telah terlaksana sangat efektif dengan presentase sebesar. Perihal ini disesuaikan dengan penelitian yang dilakukan oleh Marchat (2011) yang mengungkapkan bahwa pemberian bantuan subsidi KPR terlaksana dengan sangat efektif. Berikut rinciannya: 


\section{Tingkat Pendapatan}

Pendapatan masyarakat tidak melebihi batasan pemasukan pokok yang dipersyaratkan dalam Peraturan Menteri, yaitu pendapatan per bulan maksimum sebesar Rp. 3.500.000,00. Melalui perhitungan rumus efektivitas maka didapat dari 75 responden didapat (1)

Tabel 4.7 Ketepatan sasaran berdasarkan pendapatan

\begin{tabular}{|l|c|c|}
\hline $\begin{array}{l}\text { Batas Pendapatan (Juta Rupiah } \\
\text { dalam Satu Bulan) }\end{array}$ & Jumlah (Orang) & Presentase (\%) \\
\hline$\leq 3.500 .000$ & 53 & $70,6 \%$ \\
\hline$>3.500 .000$ & 22 & $29,4 \%$ \\
\hline
\end{tabular}

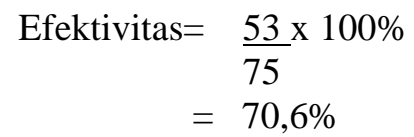

Dari hasil perhitungan diatas dapat disimpulkan bahwa ketepatan sasaran dari segi pendapataan dinilai cukup efektif

2. Belum pernah mempunyai rumah

Dari 75 responden terdapat orang yang sudah mempunyai rumah sebelumnya melalui perhitungan rumus efektivitas maka didapat (2)

Tabel 4.8 Ketepatan sasaran berdasarkan yang belum mempunyai rumah

\begin{tabular}{|c|c|c|}
\hline Belum pernah mempunyai rumah & Jumlah (Orang) & Presentase (\%) \\
\hline Sudah & 73 & $97,3 \%$ \\
\hline Belum & 2 & $2,7 \%$ \\
\hline
\end{tabular}

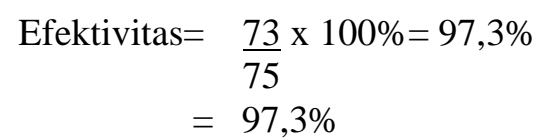

Dari hasil perhitungan diatas dapat disimpulkan bahwa ketepatan sasaran dari segi belum memiliki rumah dinilai sangat efektif

3. Belum pernah menerima subsidi perumahan untuk status kepemilikan rumah

Dari 75 responden di Perumahan Hijau 3 belum ada yang pernah menerima bantuan subsidi perumahan sebelumny melalui perhitungan efektivitas maka didapat (3)

Tabel 4.9 Ketepatan sasaran berdasarkan yang belum pernah menerima subsidi perumahan

\begin{tabular}{|c|c|c|}
\hline $\begin{array}{l}\text { Belum pernah menerima } \\
\text { subsidi perumahan }\end{array}$ & Jumlah (orang) & Presentase (\%) \\
\hline Belum & 75 & $100 \%$ \\
\hline Sudah & 0 & $0 \%$ \\
\hline
\end{tabular}




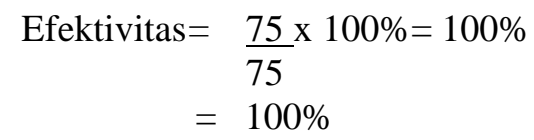

Dari perhitungan diatas dapat disimpulkan bahwa ketepatan sasaran belum pernah samasekali menerima subsidi perumahan yang dinilai sangat efektif, dikarenakan $100 \%$ berada di atas rasio efektivitas

\section{Kesimpulan}

Berdasarkan dari hasil penelitian tentang Analisis evaluasi pasca huni penghuni rumah subsidi dengan pendekatan ekonomi (Studi kasus Perumahan Hijau 3) yang bisa diambil kesimpulan, yaitu:

- KPR subsidi di Perumahan Hijau 3 dibilang cukup memberikan dampak positif pada masyarakat yang menghuni Perumahan subsidi dikarenakan dapat meringankan beban tanggungan beban ekonomi masyarakat yang telah menghuni perumahan subsidi dan membantu mendorong para masyarakat dalam membuka usaha jasa maupun perdagangan diwilayah perumahan.

- Presentase efektifitas KPR dalam pasca huni Perumahan subsidi secara keseluruhan dinilai cukup efektif.

\section{Referensi}

[1] Boediono . 2012. Teori Pertumbuhan Ekonomi. Yogyakarta: BPFE

[2] Hanum, Chalidah, 2009, Strategi Bank BTN Syariah Dalam Pembiayaan terhadap KPR Bermasalah (Studi Kasus PadaBank BTN Kantor Cabang Syariah Jakarta) (Skripsi Tidak Diterbitkan), Jakarta: Universitas Syarif HidayatullahJakarta.

[3] Mangeswuri, D. R. (2016). Kebijakan Pembiayaan Perumahan Melalui Fasilitas Likuiditas Pembiayaan Perumahan (FLPP). Policy and Housing Loan throught Housing Loan Liquidity Facility (FLPP). Jurnal Ekonomi Kebijakan Publik Vol.6, No. 1.Jakarta Pusat.

[4] Sudibyo, S. 1989. Aspek Fungsi dan Teknis Post Occupancy Evaluation

[5] Sugiyono. 2012. Metode Penelitian Pendidikan Pendekatan Kuantitatif, Kualitatif, dan R\&D. Bandung: ALFABETA. 2012 (cet. 15)

[6] Undang-Undang No. 1, 2011. Perumahan dan permukiman 